\title{
Characterization of climate impacts on a semi-arid agricultural perimeter in Morocco Abdelhaq BOUNDI ${ }^{1 *}$ and Zehor AIT YACINE ${ }^{2}$
}

1. Independent consultant, Fkih Ben Salah, Morocco.

2. Environmental Engineering, Faculty of Science and Technology -University Sultan Moulay Slimane, Béni Mellal, Morocco.

\begin{abstract}
The manifestations of climate change in precipitation, air temperature and simulated evapotranspiration for crops in the Tadla perimeter in central Morocco are examined. The study area is characterized by a semi-arid climate, with a potential agricultural vocation. This area is exposed to a scarcity of water resources for crop irrigation. To this effect, it is it is treating of rainfall in this area over 60 years (1958-2018) at 27 measuring stations and for temperature and reference evapo-transpiration (ETo) over 49 years (1969-2018) at 4 stations. Following data analysis by homogeneity tests on the agro-climatic time series (Pettitt test, Lee and Heghinian test, Buishand test and Hubert's segmentation method). It is detecting that there are time breaks on annual rainfall, mean temperature and reference evapo-transpiration at the respective years of 1978, 1995 and 1978. Because of these breaks in time, rainfall is reducing by $36 \%$, atmospheric warming is $1^{\circ} \mathrm{C}$ and the climate demand for evaporation coupled with plant transpiration increases by $13 \%$. Consequently, the water requirement increases significantly in the agricultural area of crop production.
\end{abstract}

\section{Introduction}

The present research aims to evaluate the long-term manifestations of climate change in a vulnerable semi-arid bioclimatic zone, which is most prevalent in North-West Africa, while characterizing the most relevant agroclimatic indicators, including rainfall, ambient temperature and reference evapo-transpiration of crops. It has been reported precipitation in continental regions has been effectively decreasing during last decade's in West Mediterranean and in West Africa area [1].

In this context, the Tadla perimeter a strategic Moroccan agricultural area was selected as the study area. It is located on semi-arid bioclimatic zone and is part of the important Oum Er Rbia hydraulic. Multiples changes in hydroclimatic variables have been reported in the basin, starting from the late 1970s onwards [2]: gradual rainfall decrease from the late, a relative atmospheric heating and a the gradual increase in climatic demand for evaporation, as well as the higher transpiration of the vegetation affected in this biotope.

\section{Material and methods}

\subsection{Study area}

The study area is the $3000 \mathrm{~km}^{2}$ agricultural perimeter of Tadla, situated in the semi-arid bioclimatic stage of the Beni Mellal-Khénifera region (Morocco). It is located between longitudes West $6^{\circ} 18^{\prime} 08^{\prime \prime}$ and $7^{\circ} 04^{\prime} 39^{\prime \prime}$ and latitudes North $32^{\circ} 10^{\prime} 16^{\prime \prime}$ to $32^{\circ} 40^{\prime} 10^{\prime \prime}$, and has an altitude of around $400 \mathrm{~m}$.

\subsection{Methods used}

The major agro-climatic indicators considered are precipitation, temperature and reference evapo-transpiration (ETo). ETo is commonly adopted for its compelling similarity with plant water requirements [3].

The trend of these indicators is conducted using the appropriate statistical methods typically used to test time series homogeneity, which are essentially defined as follows [4]:

-Pettitt test: This test is a modified version of the Mann-Wihtney test. It allows verifying stationarity of rainfall series. It is subdividing into two groups of data with respective sizes " $m$ " and " $\mathrm{n}$ ", whose values are grouping and are classifying by ascending order. It is following by the calculation of the sum of the ranks of elements in each group; a statistical study allows detecting the existence or absence of a break.

-Lee and Heghinian Bayesian method: It is a Bayesian method. Therefore, that is proposing a parametric approach. It is requiring a normal distribution of serial values. The absence of a break in the series is a null hypothesis.

-Buishand U-Statistics: The procedure has the same concepts and hypotheses considered in Lee and Heghinian's method, with the condition of normality of the series data studied, in particular the position of the possible break point to be identifying by Buishand's U statistics.

-Hubert segmentation: The segmentation is consisting in splitting the time series into segments. For two contiguous segments, a significant difference is then identifying as the break in the series.

The mathematical equations of these four statistical tests of homogeneity of rainfall series are reporting in detail in the publications by the authors concerned [4].

\subsection{Agro-climatic data}

\footnotetext{
* Corresponding author: boundhaq@gmail.com
} 
The agro-climatic database coms from a network of 28 climatic stations in the Tadla perimeter. The observations span 60 years (1958-2018) for precipitation and 49 years period (1969-2018) for temperature and reference evapotranspiration.

\subsection{Statistical analyses}

About analyses at time series trend, cited in paragraph 1.2 Methods used, it is used "Khronostat" software [4]. Numerical data processing is applied statistical software: "SPSS" and "R".

\section{Results and discussion}

Following the homogeneity tests conducted on the rainfall, temperature and reference evapo-transpiration (ETo) series, years of time breaks were detected. The implicit analyses by agro-climatic indicator are presenting below.

\subsection{Precipitation}

In the evolution of the annual rainfall totals, it is noted that the year 1978, a main point of the chronological break. It is illustrated in the graph in Figure 1.

It is noted that in the pre-breakdown sub-period of 1959-1978, the average rainfall is $397 \mathrm{~mm} /$ year, versus $254 \mathrm{~mm} /$ year during the period after the break (1979-2018). Therefore, the rainfall reduction rate is $36 \%$ between these two sub-periods, illustrated in the histogram graph in Figure 2.

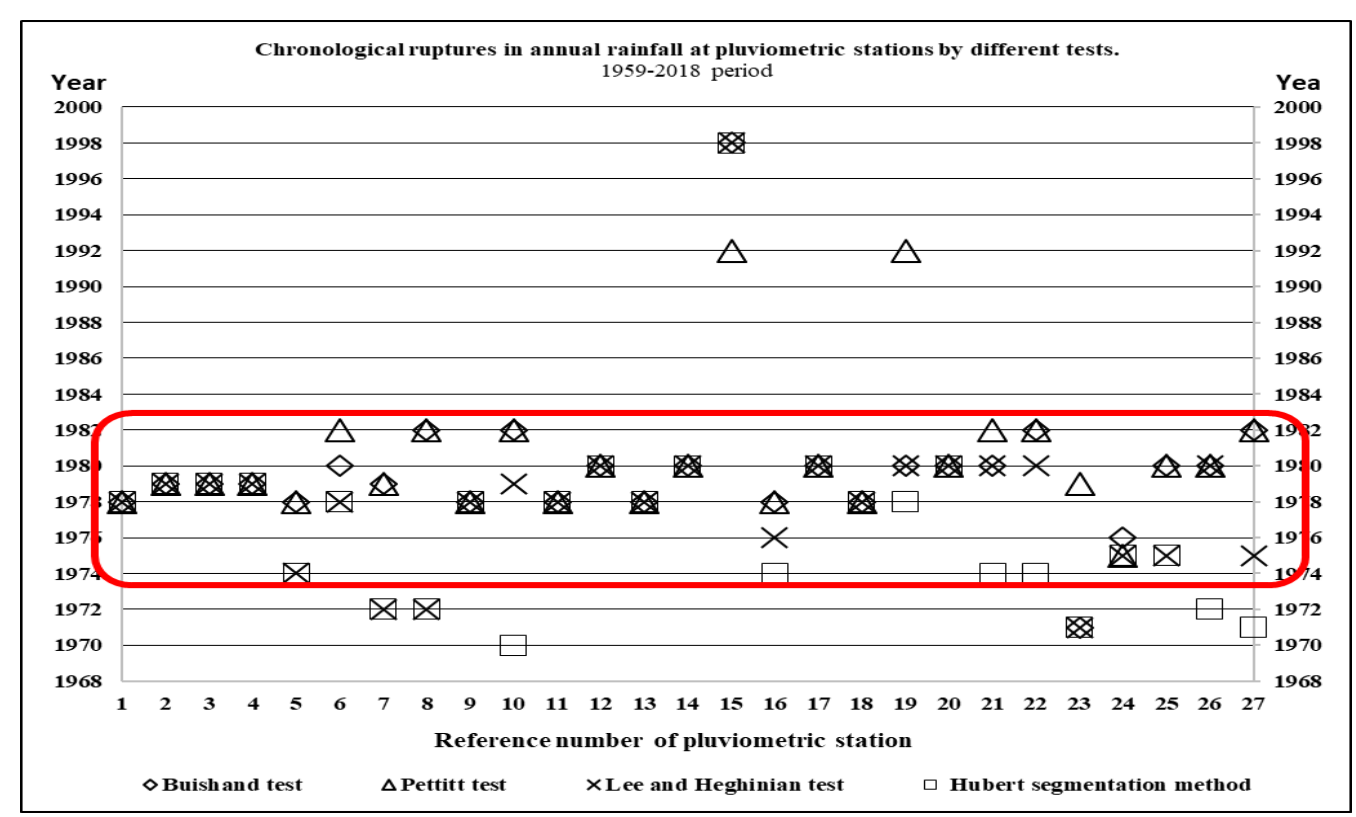

Fig. 1: Chronogram of rainfall ruptures by homogeneity tests. Observation period 1958-2018 in several station. Tadla perimeter (Morocco).

Shift in of the year 1978 is not in line with the findings in recent research works in the eastern part of the Oum Er Rbia hydraulic basin, located near the study area. However, the two studies do not cover the same periods, with 
1983-2015 observation period [5]. This is explained, by our study is more recent and with a long observation period (1958-2018).

Furthermore, our results are relatively comparable with those of other authors, who detected shifts in the rainfall regime in the same study area during the decade of the 1980 s, others studies detected a shift and a large area of North-West of Algeria between the late 1960s and the early 1970s [1;6].

The amount of reduction in rainfall after the shift is found to be $36 \%$ in this study (Figure 2). Shifts between $8 \%$ and $15 \%$ were found by [2] using a more extended time series of observations.

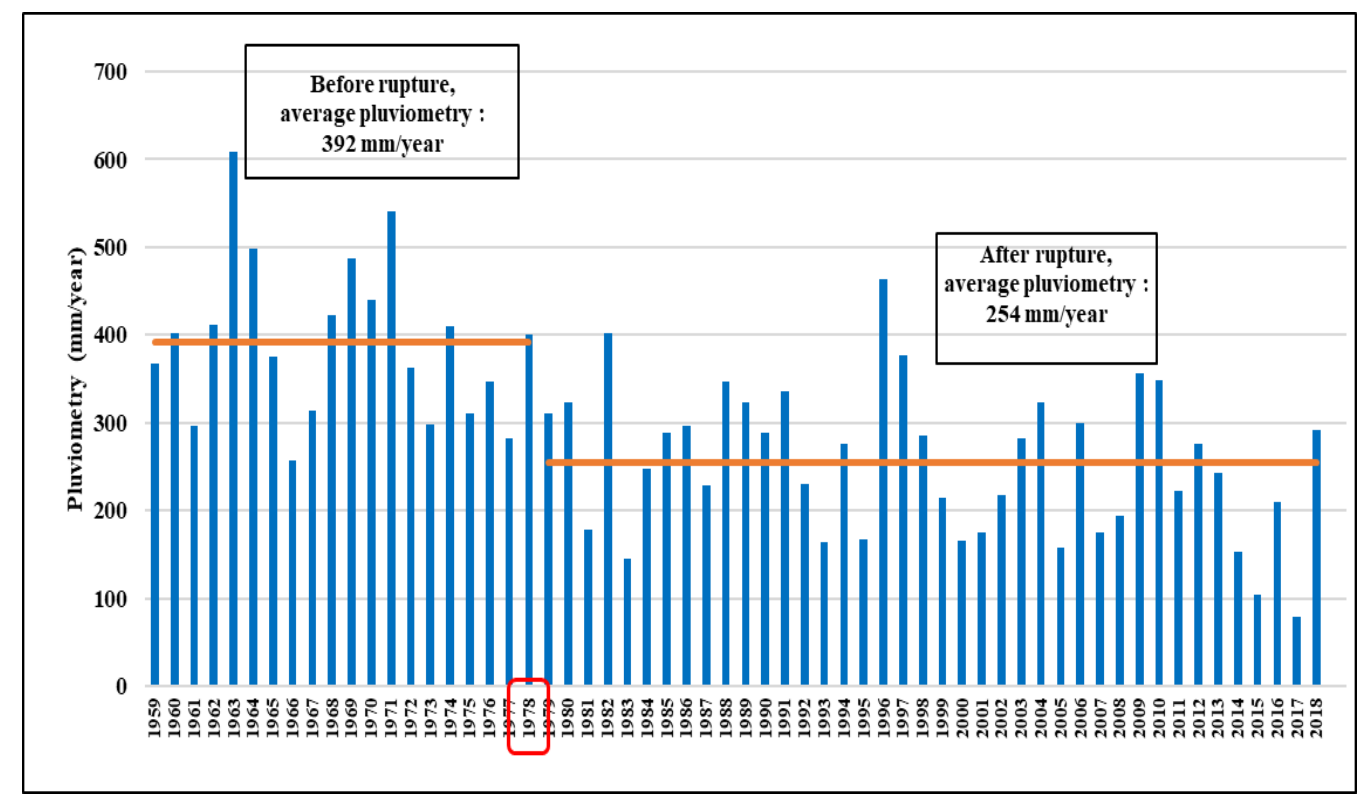

Fig. 2: Annual precipitation evolution before and after rainfall rupture. Observation period 1958-2018. Tadla perimeter (Morocco).

\subsection{Temperature}

A shift was detected in the year 1995 in the time series of average air temperature (Figure 3).

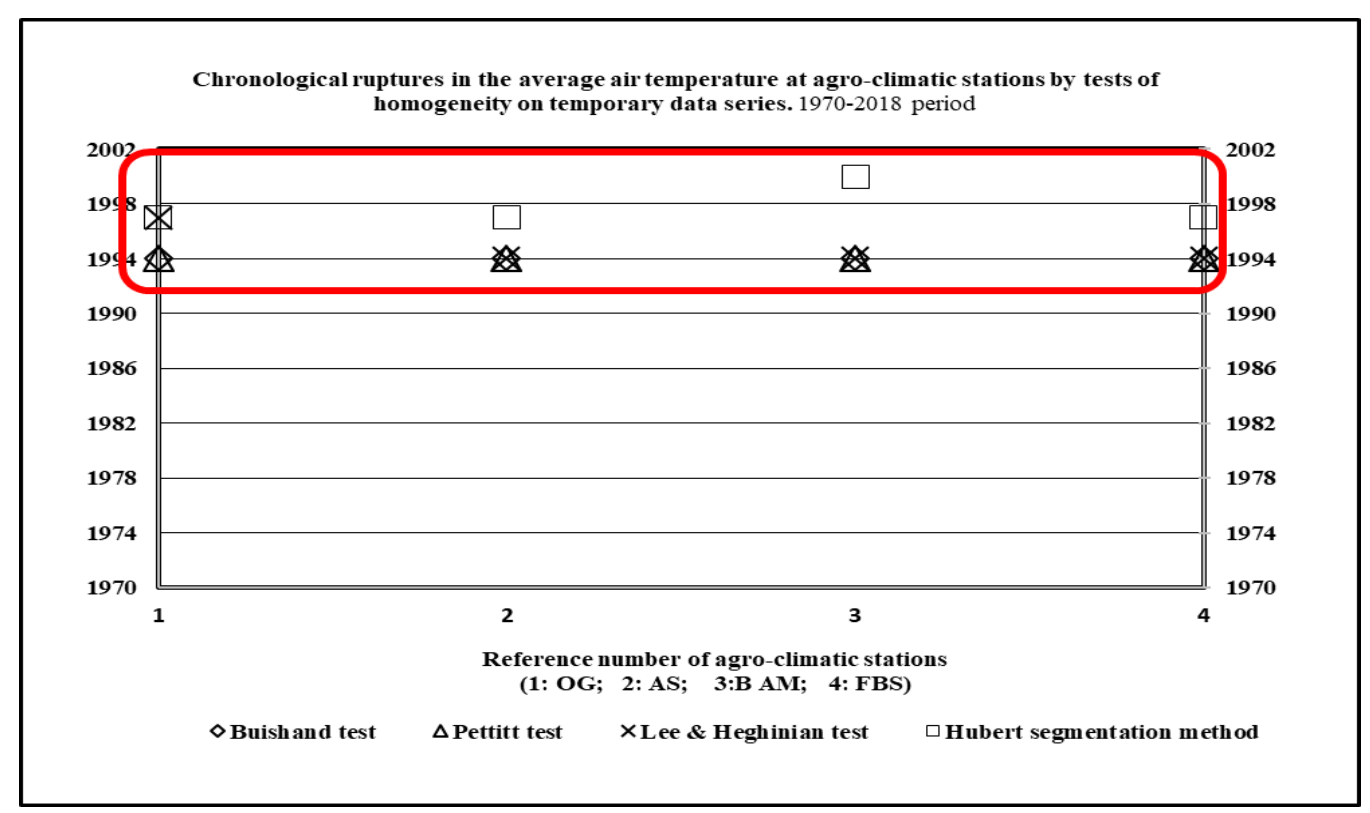

Fig. 3: Shift in mean temperature by distribution homogeneity tests. Period at 1969-2018 in several stations. In Tadla perimeter (Morocco).

In addition, the mean temperature level jumps after the time break from 18.7 to $19.7^{\circ} \mathrm{C}$. This shows an atmospheric heating (a positive deviation of $1^{\circ} \mathrm{C}$ ), which occured two decades ago (Figure 4). 


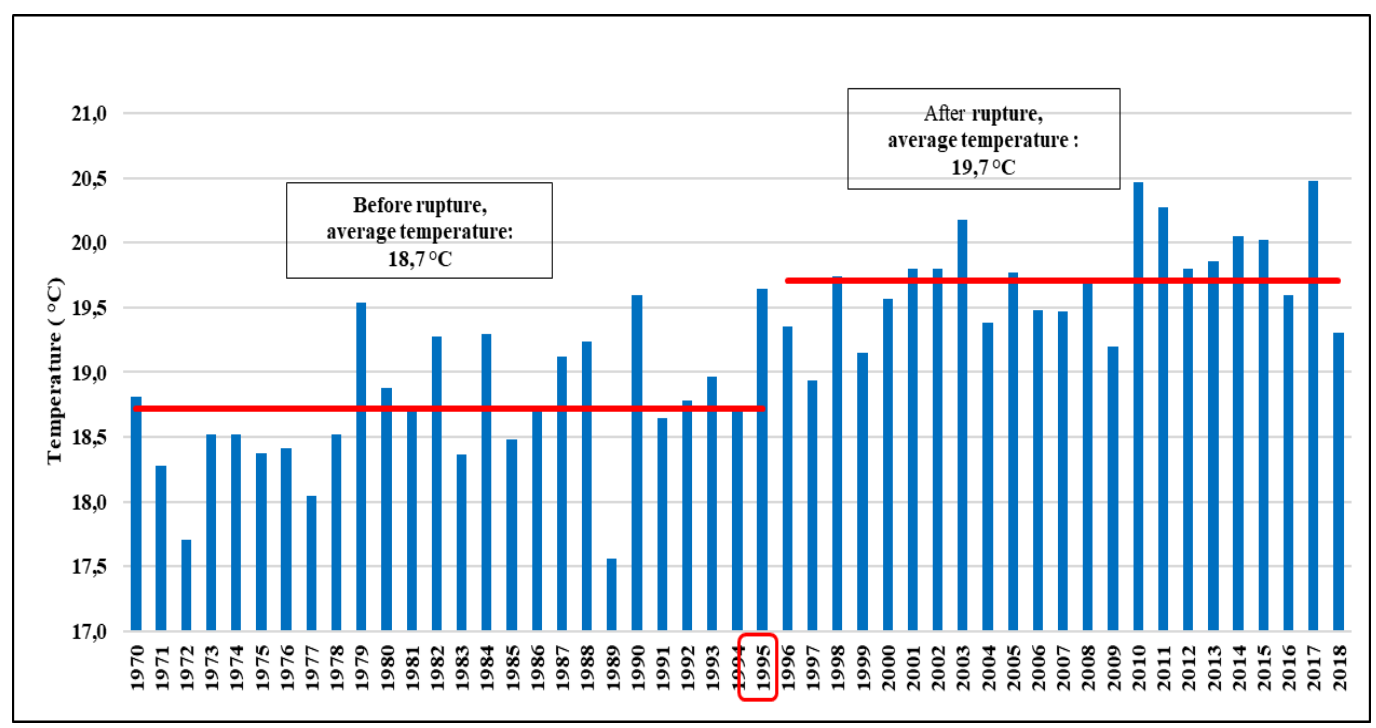

Fig. 4: Average air temperature at the Tadla perimeter (Morocco) before and after the shift.

The observed anomaly in ambient temperature $\left(+1^{\circ} \mathrm{C}\right)$ is in accordance with the same shift in at the global air temperature [7].

\subsection{Evapotranspiration}

A shift was observed in 1978 for ETo (agro-climatic indicator reference evapo-transpiration in the study area (Figure 5).

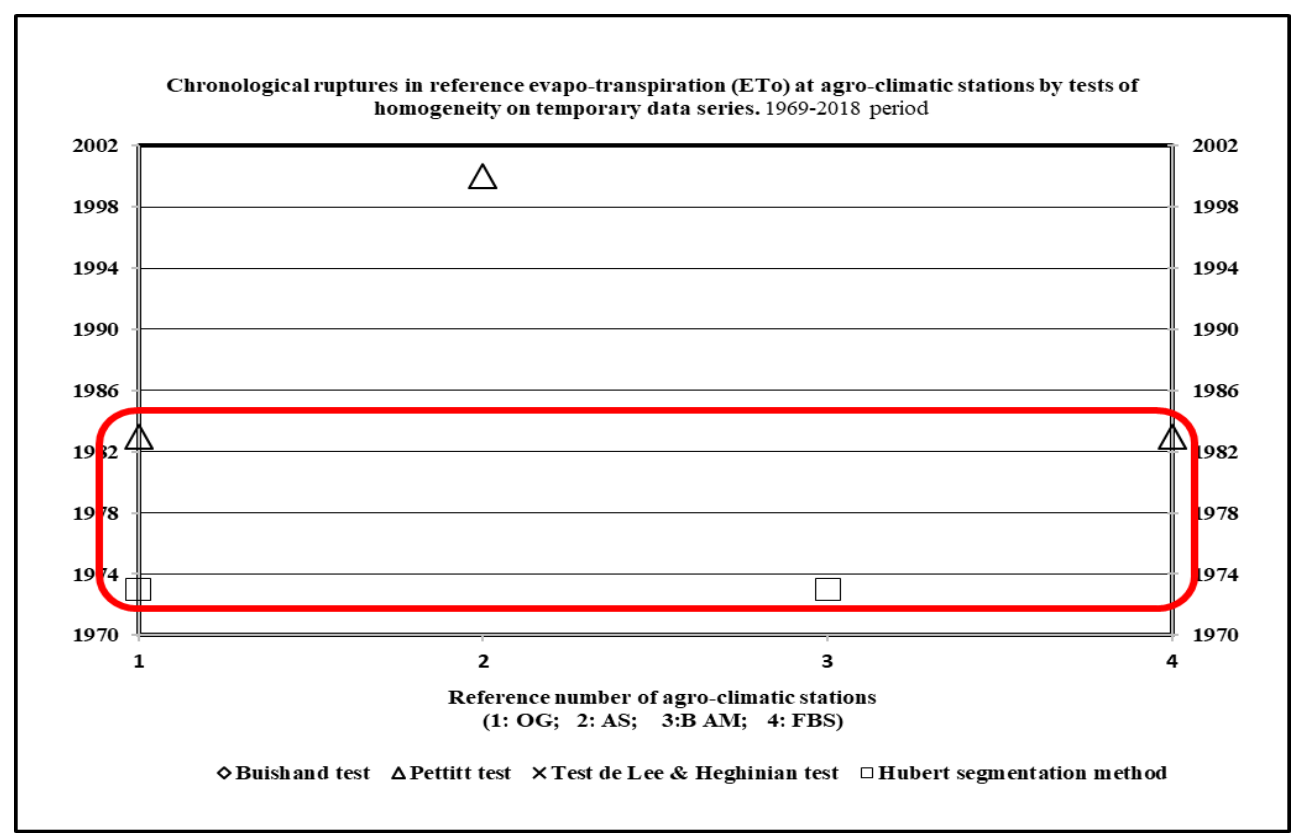

Fig. 5: Dates of time break at reference evapotranspiration (ETo) detected by homogeneity tests. Period at 1969-2018 in several stations. Tadla perimeter (Morocco).

The reference evapo-transpiration (ETo) in the study area increases by $12.5 \%$; after the shift (Figure 6). It is in the same range as $11.4 \%$ ETo change reported by [8] in the central Tunisian area with a similar semi-arid climate. 


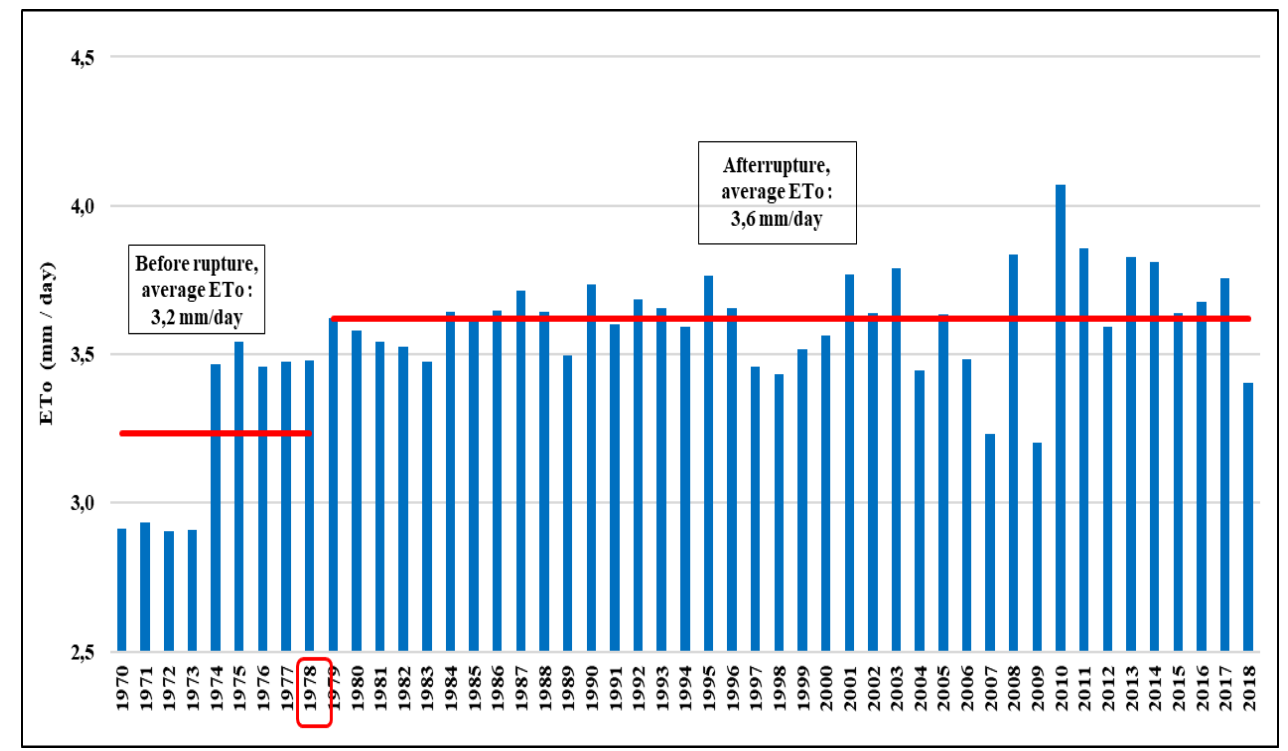

Fig. 6: Average evapo-transpiration at the Tadla perimeter (Morocco) before and after the shift. 1958-2018 period.

\section{Conclusion}

Climate change in recent decades has been observed in a semi-arid model area of potential agricultural in Morocco. This was achieved through the study of the temporal variability of pertinent bioclimatic indicators, which are of essential used in the agronomic management of crop areas; particularly for cases in the most vulnerable to water scarcity in situation of needed supplemental irrigation. The trend of decreasing rainfall over the last four decades was confirmed by this study along with atmospheric heating over the last twenty years. In addition, the climate's demand for evaporation has been increasing in combination with the increase in transpiration of the plants growing in is this area of bioclimatic stage over the last 40 years. Consequently, the water requirements of the crops in this space are expected to increase.

\section{References}

1. TAIBI S., MEDDI M., SOUAG D. and MAHE G. Larhyss Journal. Vol. 359:191-197(2013).

2. SEBBAR A., BADRI W., FOUGRACH H., HSAINE M. and SALOUI A. Sécherese. Vol. 22 (3): 139-148 (2011).

3. ALLEN R. G., PEREIRA L. S., RAES D. and SMITH M. Crop evapo-transpiration-Guidelines for computing crop water requirements-FAO Ir. \& drainage paper 56. FAO, Rome (Italy) 300. No 9: D05-109 (1998).

4. TRAORE V., NDIAYE M. L., MBOW C., GIOVANI M., SARR J., BEYE A. and DIAW A. KhronoStat Model as Statistical Analysis Tools in Low Casamance River Basin, Senegal. Edit.207: 10-22 (2017).

5. KRIMISA S., BOUCHAOUI L. and ABOURICHA S. Larhyss Journal. Vol. 30 (2017): 7-26 (2017).

6. GHENIM A. N. MEGNOUNIF A. SEDDINI A. and TERFOUS A. Sècheresse. Vol. 21 (2) (2010).

7. LENSSEN N. J. L., GAVIN A. S., HANSEN J. E., MENNE M.J., PERSIN A., RUEDY R. and ZYSS D. Improvements in the GISTEMP uncertainty model. J. Geoph. Res.: Atmos. Vol. 124 (12): 6307-6326 (2019).

8. HAJRI J. Citrus, pp: 220-225. 29 ${ }^{\text {th }}$ International Symposium. 6-9 September 2006-Université Denis Diderot Epernay (France) (2006). 